\title{
Spatial and Temporal Mapping of COVID-19 Pandemic Using GIS Technique: A Case Study of Italy
}

\author{
Farhan Ul Moazzam, M. ${ }^{1 *}$ Paracha, T. U., ${ }^{2}$ Rahman, G. ${ }^{3}$ Lee, B. G. ${ }^{*}$ and Farid, ${ }^{4}$ \\ ${ }^{1}$ Department of Civil Engineering, College of Ocean Sciences, Jeju National University, 102 jejudaehakro \\ Jeju 63243, Republic of Korea, E-mail: farhan.moazzam@gmail.com, ${ }^{*}$ leebg@jejunu.ac.kr* \\ ${ }^{2}$ Department of Pharmacology, Faculty of Pharmacy, Hamdard University, Karachi, Pakistan \\ ${ }^{3}$ Department of Geography, University of Gujrat, Gujrat, Pakistan \\ ${ }^{4}$ Department of Geography, University of Peshawar, Peshawar, Pakistan \\ *Corresponding Author
}

DOI: https://doi.org/10.52939/ijg.v17i5.2019

\begin{abstract}
Coronavirus pandemic disease (COVID-19) has spread globally. Presently, there is insufficient data regarding clinical studies and its epidemiological features. However, it is comprehended that most of the COVID-19 infected patients show mild to moderate symptoms which improve without any medical assistance attributing to enhanced immune system by generating antibodies against the viral antigens. In this comparative study, the active cases, recovered cases, deaths, and total confirmed cases from January 2020 to $23^{\text {rd }}$ August 2021 have been analyzed using a geospatial technique inverse distance weighting (IDW). Until latter, the total number of COVID-19 cases reported in Italy were 4,168,699 including 128,715 deceased, $3,904,429$ recovered and 135,555 cases were still active carriers. Out of total cases $20.76 \%$ were reported in Lombardia region with a death rate of $26.26 \%$. This mortality rate was found higher in comparison with rate followed by Emilia-Romagna (10.35\%), Piemonte (9.10\%), and Vento (9.06\%). While percentage of recovery was found variable i.e. in Lombardia 20.98\%, followed by Veneto 10.89\%, Campania 10.88\% and EmiliaRomagna 9.72\%. COVID-19 evolution in Italy has majorly affected the urban area i.e., Rome, Milan, Naples, Bologna, and Florence. Geospatial technology played a vital statistical role by tracking infected patients, active cases, and the recovered cases. Thus, it is acknowledged that geospatial techniques are an important tool in statistical evaluation of disease spread and their control among populations.
\end{abstract}

\section{Introduction}

A deadly B-coronavirus (CoV) pandemic, with patients presenting with cases of extreme pneumonia, has spread globally since origination in Wuhan, China in December 2019. It was initially designated as novel coronavirus $(2019-\mathrm{nCoV})$ by WHO and has also been labeled coronavirus disease 2019 (COVID-19) (Lu et al., 2020, World Health, 2015, Gorbalenya et al., 2020, Huang et al., 2020 and Wang et al., 2020). The International Committee on the Taxonomy of Viruses (ICTV) termed it as SARS-CoV-2 virus based on its similarity to the severe acute respiratory syndrome coronavirus (SARS-CoV) (Gorbalenya et al., 2020).

Universally COVID-19 has affected around 213 million people with 4.4 million deaths reported to WHO (WHO, 2021). Even though Chinese researchers were able to provide the SARS-CoV-2 genome sequence ( $\mathrm{Lu}$ et al., 2020) but continuous human to human transmission of this contagious virus has produced devastating effects on the human health sector. Not only human health but also world's economy has been negatively impacted to an unprecedented level (Chan et al., 2020). The potential public health risks of COVID-19 are quite high and detrimental (Gao, 2018 and Cascella et al., 2020).

In Italy, between $29^{\text {th }}$ January and $16^{\text {th }}$ June 2020 , there have been 238,720 confirmed cases of COVID-19 with 34,345 deaths reported (WHO, 2020). The fatality rate of COVID-19 infected persons in the Italian population, based on data up to March 17, was estimated to be $7.2 \%$ (Livingston and Bucher, 2020). This rate is comparatively higher than other regions of the world, for reasons based on numerous factors, such as testing strategies and population age (Onder et al., 2020), etc. The increased mortality burden has required national and international governments to employ strategies and policies worldwide to limit the spread and transmission of this contagious virus, via social distancing and other means, such as the use of 
personal protective equipment, face masks and sanitizers, etc. (Dowd et al., 2020).

Various clinical manifestations are associated with COVID-19, including a serious decline in lung function, pneumonia etc. Infected carriers may have mild to moderate symptoms or be asymptomatic (Wu and McGoogan, 2020). Increased mortality rates are observed for individuals with a pre-existing respiratory malfunction, prior asthma, any other lung disorder. Serious illness caused by COVID-19 has been clinically treated with mechanical support via ventilators and by maintaining sufficient oxygen saturation levels (Berlin et al., 2020). With the latest reports and data, studies have investigated virus' features, disease transmission, and incubation as well as management protocols (Brochard et al., 2017 and Cascella et al., 2020).

Researchers have employed various techniques and strategies to address the spread of SARS pandemics (Center, 2020 and Gatto et al., 2020). Keeping various variables such as availability of appropriate health care systems and measurements to keep up the pace with patients' needs such as isolation practices and continuously emerging spread have led to several research studies in this domain. In addition to these measures, spatial distribution analysis and explicit geographic models are needed to predict and estimate the time series analysis of COVID-19 pandemic. The demand of geospatial mapping in health sector started in $20^{\text {th }}$ century (Friede et al., 1993, Baker et al., 1995 and $\mathrm{Yu}$ and Edberg, 2005) which led to growth of information technology (IT) in the health care system. Advances in IT and its amalgamation with spatial data analysis led to the development of visualization tools for disease burden (Schriml et al., 2009 and Robertson and Nelson, 2010). Geospatial technology is a useful tool for disease mapping with its spatial and temporal information utilizing the geographical distribution of the disease (Bergquist and Rinaldi, 2010 and Saran et al., 2020).

The present study was conducted on COVID-19 spread using the GIS and mapping approach. Geospatial tools can be of essential value for obtaining knowledge, developing treatment center, understanding trends, and the mitigation of the disease. Together, these tools/methods can facilitate the design, planning, and distribution of international health aid for treatment and prevention services (Murugesan et al., 2020). The objective of the study is to provide the Spatio-temporal mapping of COVID-19 in Italy using geospatial technology for statistical evaluation of the viral spread. And to understand the influence of population density and COVID-19 cases in Italy.

\subsection{Study Area}

Italy is located in South-Central Europe but is considered a part of western Europe, with its capital is Rome. The total geographical area of Italy is $301,340 \mathrm{Km}^{2}$. It shares borders with France, Switzerland, Austria, and Slovenia. Geographically Italy consists of a peninsula delimited by the Alps mountains in the north and surrounded by sea and various islands. Italy is the third most populous country of European Union member states. The major cities in Italy are Rome, Milan, Naples, Bologna, Florence, Turin, and Genoa. According to 2019 data, the total population of Italy is $60,317,116$ with a population density of 200.16 people/Sq.km (Figure 1). Most populous region I Italy is Lombardia while the least is Valle d'Aosta (Figure $1)$.

The overall representation of COVID-19 statistics in Italy are shown above in Figure 2. A total of 4,168,699 cases were reported from the last week of January 2020 till date. Out of the total $4,168,699$ cases, $93.66 \%$ have completely recovered, but unfortunately $3.09 \%$ of the infected people lost their lives while fighting the deadly virus and $3.25 \%$ cases are still active (Figure 2).

\section{Material and Methods}

COVID-19 data for Italy was obtained from various sources (ISS, 2020, MOH, 2020 and Outbreak, 2020). The data used in this study are the number of COVID-19 confirmed cases, deaths, active patients, and recoveries. In the present study, to show the pattern of disease transmission and forecast, an interpolation technique was used, specifically, the Inverse Distance Weighted (IDW) method. Initially the data was downloaded from available sources, and it was set according to the objective of the study. The downloaded data was in excel sheets for all regions of Italy with its latitude and longitudinal information, number of confirmed cases, deaths, recoveries, and active cases. The shapefile of regions of Italy was downloaded from (DIVA-GIS) website. Consequently, the shapefile of regions was imported to ArcGIS software, the excel file with latitude and longitude information was also imported to the software and then converted it to shapefile format, eventually, the IDW technique was applied on it and maps of total cases, total deaths, total recovered cases and active cases were prepared in ArcGIS software. 


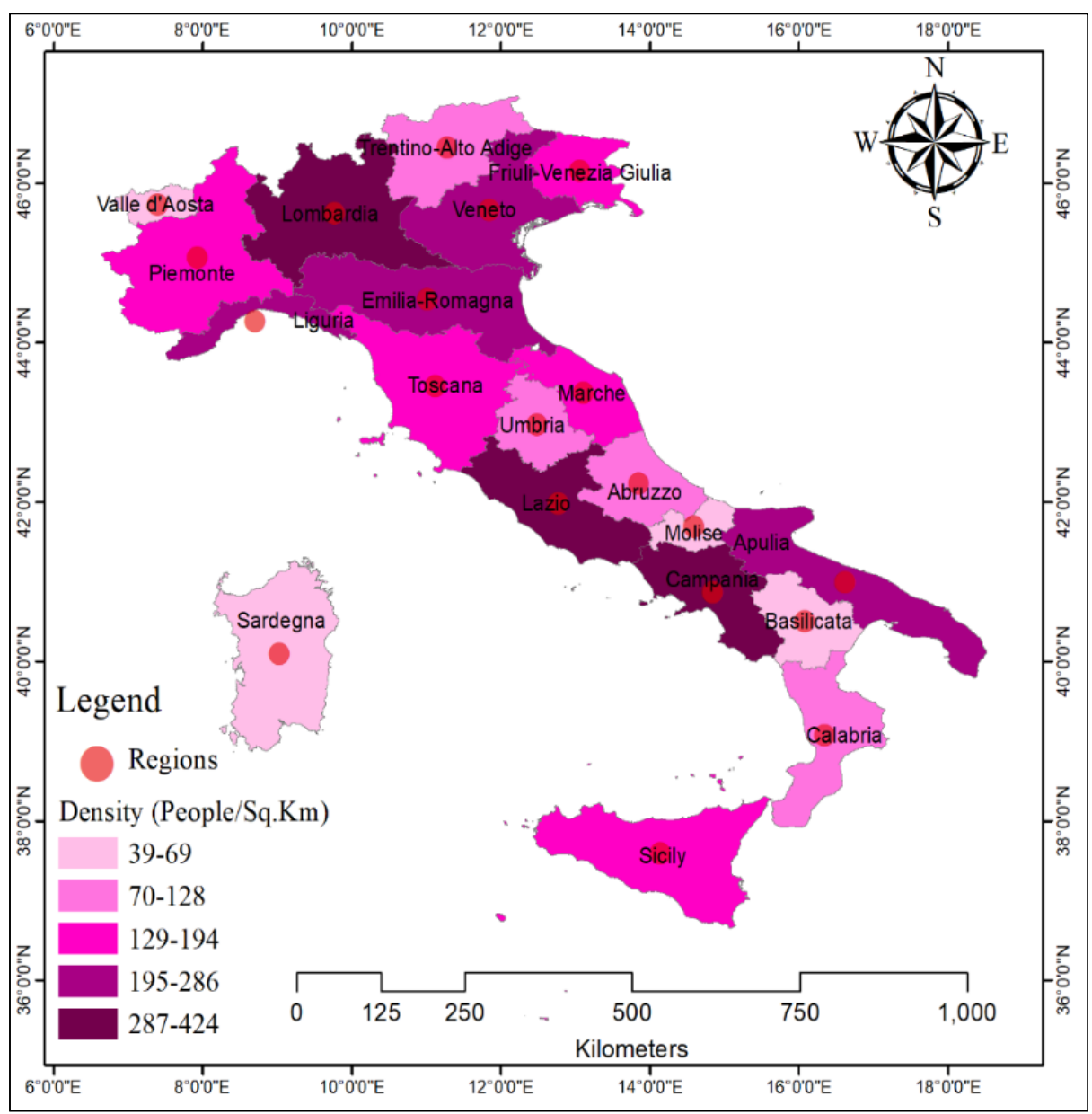

Figure 1: Study area and population density/Sq.km

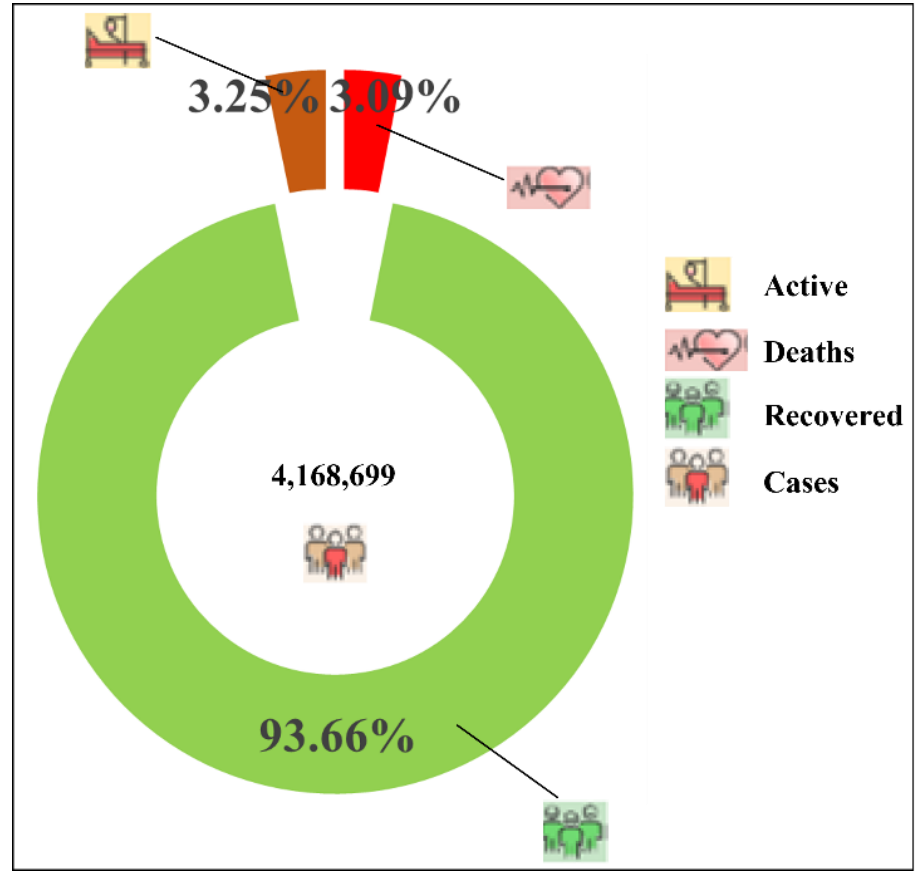

Figure 2: Statistics of COVID-19 in Italy (23 ${ }^{\text {rd }}$ August 2021) 


\subsection{Interpolation IDW}

IDW is based on the concept of Tobler's first law (the first law of geography) from 1970. It states that everything is related to everything else, but nearer things are more related than distant things. The IDW was developed by the U.S. National Weather Service in 1972 and is classified as a deterministic method since it does not require calculations to meet specific statistical assumptions. Thus IDW is different from stochastic methods (e.g., Kriging and TRA) (Chen and Liu, 2012). The spatial interpolation (IDW) method is based on the function of inverse distances, in which weight increases as the distance decreases and vice versa. This means that data points with known values are used to estimate the values of unknown points. The necessities of known points are to discriminate spatial interpolation from isopleth mapping, which uses allocated points such as polygon centroids for interpolation.

Basic theory in spatial interpolation is the value to be assessed at any point is more influenced by near known points than those that are farther away. While the assumption of a random process is usually mandatory for a stochastic method, Inverse Distance weighted (IDW) interpolation is an exact method that estimates the value of a point that is influenced by nearby known points, more than those farther away. The general equation of the IDW method is:

$$
\mathrm{K}_{\mathrm{xy}}=\frac{\sum_{i=1}^{N} \mathrm{~K}_{\mathrm{i}} \mathrm{W}_{\mathrm{i}}}{\sum_{i=1}^{N} \mathrm{~W}_{\mathrm{i}}}
$$

Equation 1

where $K_{i}$ is the control value for the Ith sample point, $\mathrm{W}_{\mathrm{i}}$ represents a weight determining the relative importance of individual control point $\mathrm{K}_{\mathrm{i}}$ in the interpolation process, $K_{x y}$ is the point to be estimated and $\mathrm{N}$ is the number of sample points (Bartier and Keller, 1996).

\section{Results}

There was a total of 4,168,699 cases reported between January 2020 and 23 ${ }^{\text {rd }}$ August 2021 (Table 1). In this study, the regional data was collected and linked with the point data. The data from 20 regions in Italy were analyzed to determine variability. The IDW technique showed the status and magnitude of the infection disease spread (COVID-19) in Italy using ArcGIS 10.5. Interpolation using IDW was applied to predict the spread of the coronavirus in Italy. As of August 23rd, 2021, a total of 135,555 (3.25\%) COVID-19 cases are still active in Italy. The map obtained from IDW of active cases as of $23^{\text {rd }}$ August 2021 was divided into eight classes using the natural break classification method. The patterns of classes were below $4,759,4,760$ to $5,982,5,983$ to $7,299,7,300$ to $8,709,8,710$ to $10,403,10,404$ to $13,224,13,225$ to 17,739 , and more than 17,7340, as shown in Figure 3(a).

Table 1: Region wise breakdown of COVID-19 Statistics in Italy

\begin{tabular}{|c|c|c|c|c|}
\hline Region & Cases & Deaths & Recovered & Active \\
\hline Abruzzo & 78323 & 2520 & 73550 & 2253 \\
\hline Apulia & 261641 & 6694 & 250316 & 4631 \\
\hline Basilicata & 28444 & 597 & 26569 & 1278 \\
\hline Calabria & 75549 & 1299 & 70194 & 4056 \\
\hline Campania & 441753 & 7682 & 424701 & 9370 \\
\hline Emilia Romagna & 407449 & 13324 & 379393 & 14732 \\
\hline Firuli Venezia Giulia & 109913 & 3796 & 105206 & 911 \\
\hline Lazio & 371257 & 8484 & 345696 & 17077 \\
\hline Liguria & 108599 & 4378 & 102195 & 2026 \\
\hline Lombardia & 865282 & 33800 & 819181 & 12301 \\
\hline Marche & 109115 & 3045 & 103124 & 2946 \\
\hline Molise & 14139 & 493 & 13458 & 188 \\
\hline Piemonte & 50660 & 11711 & 35367 & 3582 \\
\hline Sardegna & 69674 & 1560 & 60221 & 7893 \\
\hline Sicilia & 265673 & 6239 & 235288 & 24146 \\
\hline Toscana & 266785 & 6978 & 247610 & 12197 \\
\hline Trento & 121791 & 2549 & 118147 & 1095 \\
\hline Umbria & 60876 & 1427 & 57562 & 1887 \\
\hline Valle d Aosta & 11982 & 473 & 11362 & 147 \\
\hline Veneto & 449794 & 11666 & 425289 & 12839 \\
\hline *Ministry of Health, Italy $\left(23^{\text {rd }}\right.$ August 2021$)$ & & & \\
\hline
\end{tabular}




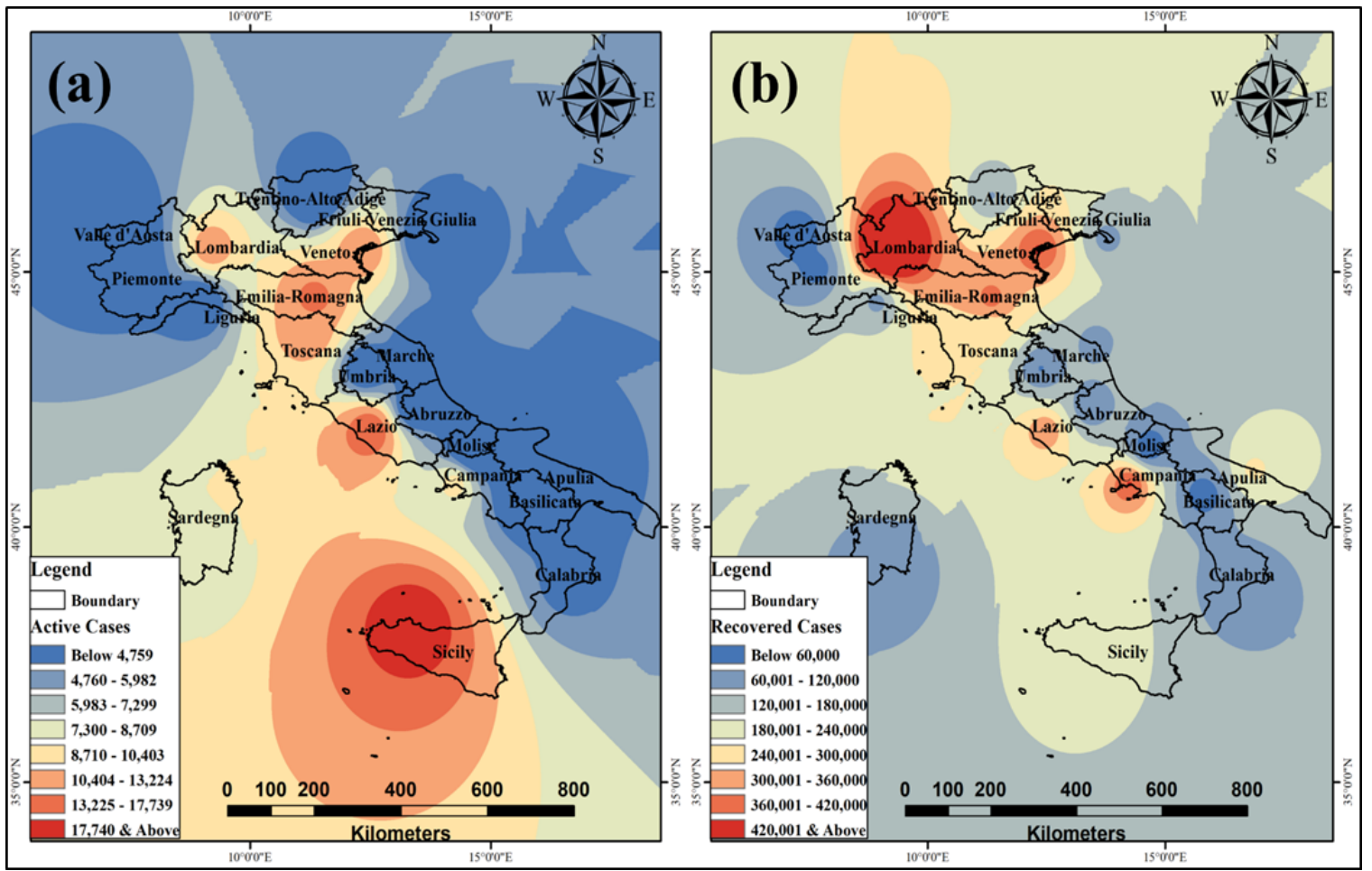

Figure 3: Spatial distribution of Coronavirus in Italy (a) Active cases (b) Recovered cases

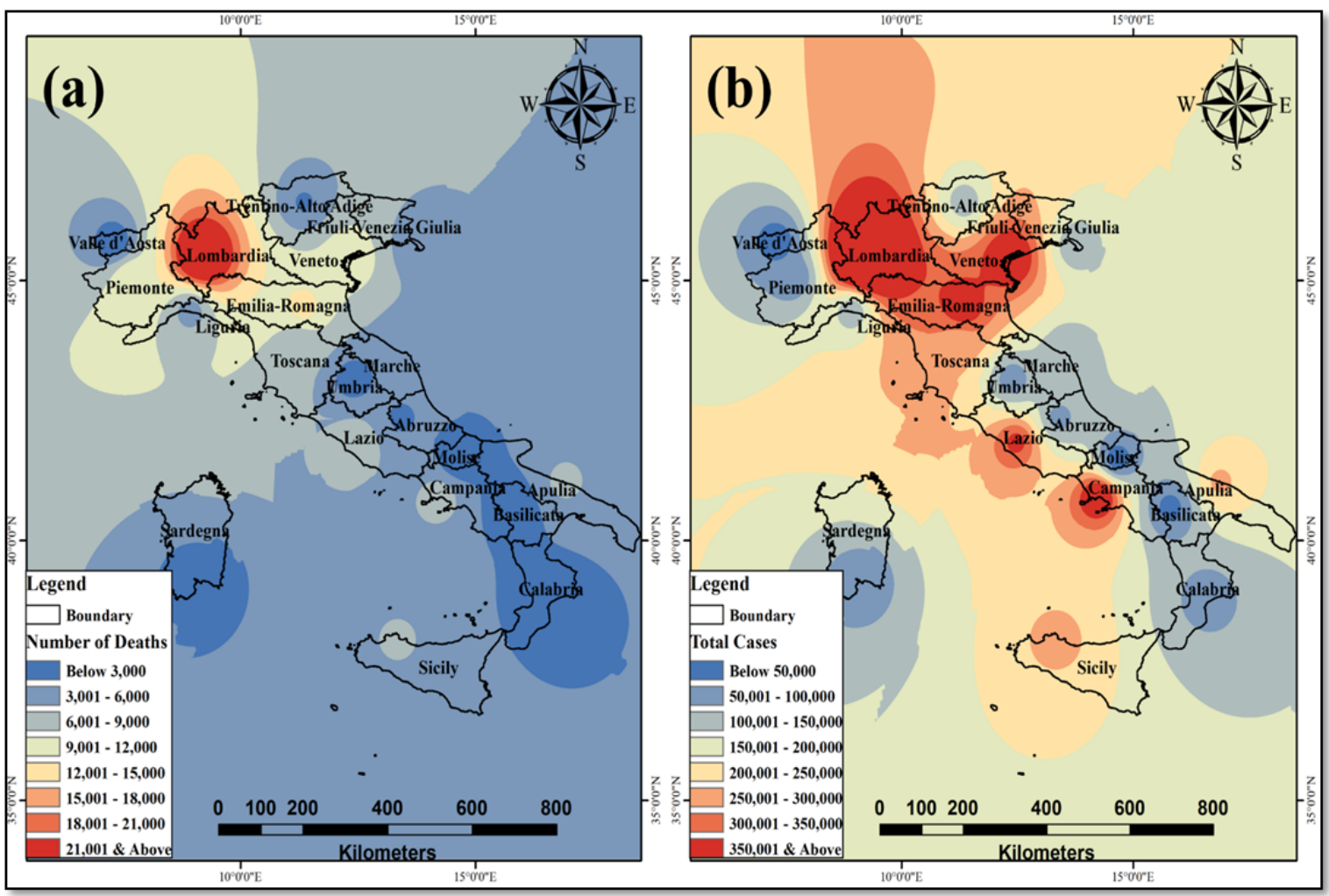

Figure 4: Spatial distribution of coronavirus in Italy (a) Total deaths (b) Total cases 
Table 2: Association between population density and COVID-19 variables using Pearson correlation

\begin{tabular}{|c|c|c|c|c|}
\hline Variables & Test Statistics (t) & $\begin{array}{c}\text { Degree of } \\
\text { freedom (df) }\end{array}$ & P value & $\begin{array}{c}\text { Correlation Co- } \\
\text { efficient }\end{array}$ \\
\hline Active Cases & 2.929 & 18 & 0.009 & 0.323 \\
\hline Total Deaths & 2.727 & 18 & 0.014 & 0.292 \\
\hline Recovered Cases & 2.867 & 18 & 0.010 & 0.313 \\
\hline Confirmed Cases & 2.898 & 18 & 0.010 & 0.318 \\
\hline
\end{tabular}

The various regions in Italy are at higher risk based on population density. A higher number of active cases was revealed in the Sicily region (18\%) followed by Lazio $12 \%$ and $20 \%$ of active cases found in northern regions (Lombardia, Emilia Romagna). To understand the influence of population density and COVID-19 cases, a Pearson correlation coefficient was performed using COVID-19 data. There was a positive correlation seen in the number of active cases and population density [where $\mathrm{r}(18)=0.323)$ ] (Table 2 ).

Figure $3 \mathrm{~b}$ showed the spatial distribution of recovered cases. It can be observed that densely populated region (Lombardia) has the highest number of recovered cases which is followed by Campania and Veneto (10.88\% \& $10.89 \%)$ respectively. The data presented in Table 2 shows positive association between recovered coronavirus cases and population density [where $\mathrm{r}(18)=0.313)$ ]. A total of 128,715 deaths have been officially reported as of $23^{\text {rd }}$ August 2021 in Italy. According to the Ministry of Health, Lombardia region, which has a population density of 421 people/Sq. Km, alone reported 33,800 deaths due to coronavirus. Nearly 13,324 (10.35\%), 11,666 (9.06\%), 6978 $(5.42 \%)$ and $6694(5.20 \%)$ deaths have been reported in the regions of Emilia-Romagna, Veneto, Toscana and Apulia, respectively (Figure 4a). Table 2 clearly depicts the relationship between total deaths caused by COVID-19 and population density [where $r(18)=0.292)]$.

After Wuhan, China, Italy was the next hotspot of infectious virus. The first corona positive case was detected in Italy on the $31^{\text {st }}$ of January, 2020 when two Chinese tourists visited Rome (Severgnin, 2020) and a week later an Italian man returned from China and was found to be positive (Anzolin and Amante, 2020). Later a cluster of positive cases was detected in the Lombardia region (Elisa Anzolin, 2020 and Ravizza, 2020) and then in the first half of March the virus spread all over the country (Redazione, 2020). The resulting COVID-19 infections caused a major health burden and emergency scenario across Italy. It can be observed from Figure $4 \mathrm{~b}$ below that Lombardia has the highest number of confirmed cases $(865,282)$ which has kept the government on its toes due to sharp surge in the number of cases. Veneto, Campania, Emilia Romagna, Lazio, Toscana, and Apulia with $10.79 \%, 10.60 \%, 9.77 \%, 6.40 \%$ and $6.28 \%$ of the cases, respectively. The huge number of COVID-19 cases has posed a threat to the citizens of Italy and the nation's economy.

A correlation was found between the number of COVID-19 cases and the populations of various regions in Italy $[$ where $\mathrm{r}(18)=0.318)$ ] (Table 2$)$.

\section{Discussion}

The COVID-19 disease has triggered major health loads all over the country. It was found that the Lombardia region has the highest number of cases followed by Veneto, Campania, Emilia-Romagna, and Toscana. Valle d Aosta has the lowest number of confirmed cases, deaths, and active cases. Lombardia also has the highest rate of deaths. The mortality rate in Lombardia is comparatively very high. Doctors and paramedic staff play a very crucial role in the COVID-19 pandemic by treating infected cases. The overall high recovery rate and low death rate in Italy indicate the country has better medical facilities as compared to various countries e.g., India, Brazil, Pakistan

In addition to impacts on human health, COVID19 and the resulting population lockdown have also affected Italy's economy, as multiple factories have been closed due to the national emergency. The accommodation sector and food services were hardest hit due to emergency measures and the ban on tourism. During 2020, 8.9\% of GDP declined in Italy as compared to other countries i.e., 3.5\% (USA), 2.2\% (Switzerland) (Torre et al., 2021). Northern Italy was knocked out by coronavirus infections, but the economically deprived parts of southern Italy suffered the most from lockdown (Nadeau and Donato, 2020).

\section{Conclusion}

This research work was carried out using geospatial technology to show the spatial distribution of coronavirus disease in Italy. It is noteworthy that strict steps taken to control the spread of the coronavirus disease during study period were likely responsible for the reductions in daily cases and daily deaths observed after mid-April, as well as the 
spike in the number of daily recovered cases. The pattern of its spatial distribution was studied using a geospatial approach. The study revealed that the most populous region of Italy (Lombardia) suffered highly from the coronavirus, with $20.76 \%$ of total cases with $26.76 \%$ of total deaths (Table 1).

A GIS-based spatial interpolation (IDW) approach was used to identify the prospective disease risk areas in Italy. The IDW analysis of spatial interpolation layers and apparent weight of the conditioning factors were also prepared. Analysis of the spatial distribution patterns may offer valuable information to support government monitoring and to image the extent of virus' spread through small and large areas. This study would be appropriate for the relevant departments to carry out detailed studies on the spread of virus and environmental control in the study area. Moreover, the approach does not merely proscribe the foretell mapping of various zones of the country but can also demonstrate the level of improbability in the forecasts, which could be helpful for other countries.

Data Availability: All data used in this manuscript are publicly available. COVID-19 epidemiological data for Italy are available at https://github.com/pcm-dpc/COVID-19.

Administrative boundaries area is available at http://www.diva-gis.org/gdata. Population census data are available at http://dati.istat.it/Index.aspx?QueryId=18460. National level COVID-19 daily updated data is available at https://ourworldindata.org/coronavirus

\section{Acknowledgement}

This research was supported by the 2021 scientific promotion program funded by Jeju National University.

\section{References}

Anzolin, E. and Amante, A., 2020, First Italian Dies of Coronavirus as Outbreak Flares in North. Reuters. Retrieved from https://www.reuters.com/article/us-china-health-italyidUSKBN20F0UI.

Baker, E. L., Andrew, F., Anthony, M. and David, A., 1995, CDC's Information Network for Public Health Officials (INPHO): A Framework for Integrated Public Health Information and Practice. Journal of Public Health Management and Practice, Vol. 1(1), 43-47.

Bartier, P. M. and Keller, C. P., 1996, Multivariate Interpolation to Incorporate Thematic Surface Data Using Inverse Distance Weighting (IDW). Computers \& Geosciences, Vol. 22(7), 795-799.
Bergquist, R. and Rinaldi, L., 2010, Health Research Based on Geospatial Tools: A Timely Approach in a Changing Environment. Journal of helminthology, Vol. 84(1), 1-11.

Berlin, D. A., Roy, M., Gulick. and Martinez, F. J., 2020, Severe Covid-19. New England Journal of Medicine. Vol. 383, 2451-2460, DOI: 10.1056/NEJMcp2009575.

Brochard, L., Slutsky, A. and Pesenti, A., 2017, Mechanical Ventilation to Minimize Progression of Lung Injury in Acute Respiratory Failure. American Journal of Respiratory and Critical Care Medicine, Vol. 195(4), 438-442.

Cascella, M., Rajnik, M., Aleem, A., Dulebohn, S. C. and Napoli, R. D., 2020, Features, Evaluation and Treatment Coronavirus (COVID-19) Statpearls [internet]: StatPearls Publishing.

Center, C., 2020, Coronavirus COVID-19 Global Cases by the Center for Systems Science and Engineering (CSSE) at Johns Hopkins University.

Chan, J. F. W., Yuan, S., Kok, K. H., To, K. K. W., Chu, H., Yang, J., Xing, F., Liu, J., Yip, C. C.Y. and Poon, R. W., 2020, A Familial Cluster of Pneumonia Associated with the 2019 Novel Coronavirus Indicating Person-to-Person Transmission: A Study of a Family Cluster. The Lancet, Vol. 395(10223), 514-523.

Chen, F. W. and Liu, C. W., 2012, Estimation of the Spatial Rainfall Distribution Using Inverse Distance Weighting (IDW) in the Middle of Taiwan. Paddy and Water Environment, Vol. 10(3), 209-222.

Dowd, J. B., Andriano, L., Brazel, D., Rotondi, V., Block, P., Ding, X., Liu, Y. and Mills, M. C., 2020, Demographic Science Aids in Understanding the Spread and Fatality Rates of COVID-19. Proceedings of the National Academy of Sciences, Vol. 117(18), 9696-9698. doi:10.1073/pnas.2004911117.

Elisa Anzolin, A. A., 2020, Coronavirus Outbreak Grows in Northern Italy, 16 Cases Reported in one Day. Reuters. Retrieved from https://www.reuters.com/article/us-china-healthitaly/coronavirus-outbreak-grows-in-northernitaly-16-cases-reported-in-one-dayidUSKBN20F0UI.

Friede, A., Reid, J. A. and Ory, H. W., 1993, CDC WONDER: A Comprehensive On-Line Public Health Information System of the Centers for Disease Control and Prevention. American Journal of Public Health, Vol. 83(9), 12891294. doi:10.2105/ajph.83.9.1289. 
Gao, G. F., 2018, From "A" IV to "Z" IKV: Attacks from Emerging and Re-Emerging Pathogens. Cell, Vol. 172(6), 1157-1159.

Gatto, M., Bertuzzo, E., Mari, L., Miccoli, S., Carrao, L., Casagrandi, R. and Rinaldo, A. 2020, Spread and Dynamics of the COVID-19 Epidemic in Italy: Effects of Emergency Containment Measures. Proceedings of the National Academy of Sciences, Vol. 117(19), 10484-10491.

Gorbalenya, A. E., Susan, C. B., Ralph, S. B., Raoul J., Christian D., Anastasia, A. G., Bart, L. H., Haagmans, C. L., Andrey, M. L., Benjamin, W. N., Dmitry, P., Stanley, P. and Leo, L. M., 2020, The Species Severe Acute Respiratory Syndrome-Related Coronavirus: Classifying 2019-nCoV and Naming it SARS-CoV-2. Nature microbiology, Vol. 5(4), DOI:10.1038/s41564-020-0695-z.

Huang, C., Wang, Y., Lie, W., Ren, L., Zhao, J., Hu, Y., Zhang, L., Fan, G., Xu, J., Gu, X., Cheng, Z., Wei, Y., Wu, W., Xie, X., Gao, H. and Wang, J. 2020, Clinical Features of Patients Infected with 2019 Novel Coronavirus in Wuhan, China. The lancet, Vol. 395(10223), 497-506.

ISS, 2020, Epidemia COVID-19. Retrieved 01 June 2020, from Istituto Superiore di Sanità https://www.iss.it/coronavirus

Livingston, E. and Bucher, K., 2020, Coronavirus Disease 2019 (COVID-19) in Italy. Jama, Vol. 323(14), 1335-1335.

Lu, H., Stratton, C. W. and Tang, Y. W., 2020, Outbreak of Pneumonia of Unknown Etiology in Wuhan China: the Mystery and the Miracle. Journal of Medical Virology., Vol. 92(4), 401402.

Lu, R., Zhao, X., Li, J., Niu, P., Yang, B., Wu, H., Wang, W. and Song, H., 2020,. Genomic Characterisation and Epidemiology of 2019 Novel Coronavirus: Implications for Virus Origins And Receptor Binding. The lancet, Vol. 395(10224), 565-574.

MOH, 2020, PCM-DPC Data by Ministry of Health. Ministero Della Salute Retrieved from http://www.salute.gov.it/.

Murugesan, B., Karuppannan, S., Mengistie, A.T. and Gopalakrishnan, G., 2020, Distribution and Trend Analysis of COVID-19 in India: Geospatial Approach. J. Geographical Studies, Vol. 4(1), 1-9.

Nadeau, B. L. and Donato, V. D., 2020, As Northern Italy is Ravaged By Coronavirus, there's Trouble Brewing Down South. CNN. Retrieved from https://edition.cnn.com/2020/04/04/europe/southern-italy-coronavirus-blackeconomy-intl/index.html.
Onder, G., Rezza, G. and Brusaferro, S., 2020, Case-fatality Rate and Characteristics of Patients Dying in Relation to COVID-19 in Italy. Jama, Vol. 323(18), 1775-1776.

Outbreak, 2020, Hi This is Outbreak. Retrieved 01 June 2020 https://outbreak.cc/index.html .

Ravizza, S., 2020, Coronavirus: First Cases in Milan. What do We Know about the New Infections in Lombardy, Veneto and Piedmont. Corriere della Sera. Retrieved from https://www.corriere.it/cronache/20_febbraio_22 /coronavirus-italia-nuovi-contagi-lombardiaveneto-245e72d4-5540-11 ea-84182150c9ca483e.shtml.

Redazione, 2020, Coronavirus. Hit all regions. Civil Protection: here are the updated numbers. Avvenire. Retrieved from https://www.avvenire.it/attualita/pagine/coronavirus-aggiornamento5-marzo-2020.

Robertson, C. and Nelson, T. A., 2010, Review of Software for Space-Time Disease Surveillance. International Journal of Health Geographics, Vol. 9(1), 16. doi:10.1186/1476-072X-9-16.

Saran, S., Singh, P., Kumar, V. and Chauhan, P., 2020, Review of Geospatial Technology for Infectious Disease Surveillance: Use Case on COVID-19. Journal of the Indian Society of Remote Sensing, 1-18.

Schriml, L. M., Arze, C., Nadendla, S., Ganapathy, A., Felix, V., Mahurkar, A., Phillippy, K., Gussman, A., Angiuoli, S., Ghedin, E., White, O. and Hall, N., 2009, GeMInA, Genomic Metadata for Infectious Agents, a geospatial Surveillance Pathogen Database. Nucleic Acids Research, 38(suppl_1), D754-D764. doi:10.1093/nar/gkp832.

Severgnin, C., 2020, Coronavirus: Primi Due Casi in Italia. Corriere della sera Retrieved from https://www.corriere.it/cronache/20_gennaio_30 /coronavirus-italia-corona-9d6dc436-4343-11 eabdc8-faflf56f19b7.shtml?refresh_ce-cp.

Torre, E., Colombo, G. L., Matteo, S. D., Martinotti, C., Valentino, C. M., Rebora, A., Cecoli, F., Monti, E., Galimberti, M., Bartolo, P. D., Gaggioli, G. and Bruno, G. M., 2021, Economic Impact of COVID-19 Lockdown on Italian NHS: Focus on Diabetes Mellitus. ClinicoEconomics and Outcomes Research: CEOR, Vol. 13, DOI:10.24911/IJMDC.511609175889.

Wang, D., Hu, H. and $\mathrm{Hu}, \mathrm{C}$, 2020, Clinical Characteristics of 138 Hospitalized Patients with 2019 Novel Coronavirus-Infected Pneumonia in Wuhan, China. Jama, Vol. 323(11), 1061-1069. 
WHO, 2015). World Health Organization best Practices for the Naming of New Human infectious diseases. Retrieved from Geneva: https://apps.who.int/iris/handle/10665/163636.

WHO, 2020, World Health Emergency Dashboard. Retrieved from https://covid19.who.int/region/euro/country/it.

WHO, 2021, WHO Coronavirus Disease (COVID19) Dashboard. Retrieved from https://covid19.who.int/
Wu, Z. and McGoogan, J. M., 2020, Characteristics of and important Lessons from the Coronavirus Disease 2019 (COVID-19) Outbreak in China: Summary of a Aeport of 72314 Cases from the Chinese Center for Disease Control and Prevention. Jama, Vol. 323(13), 1239-1242.

Yu, V. L. and Edberg, S. C., 2005, Global Infectious Diseases and Epidemiology Network (GIDEON): A World Wide Web-Based Program for Diagnosis and Informatics in Infectious Diseases. Clinical Infectious Diseases, Vol. 40(1), 123-126. doi:10.1086/426549. 